\title{
A COMPARISON OF ORGANICALLY AND CONVENTIONALLY GROWN ARTICHOKES: PHENOLIC CONSTITUENTS, ANTIOXIDANT AND ANTIBACTERIAL ACTIVITIES
}

\author{
A.B. YILDIRIM ${ }^{\mathrm{a}}$, S. BASAY ${ }^{\mathrm{b}}$ and A.U. TURKER ${ }^{\mathrm{c*}}$ \\ ${ }^{a}$ Department of Field Crops, Faculty of Agriculture and Natural Sciences, Bolu Abant Izzet Baysal University, \\ Bolu. Turkey \\ ${ }^{\mathrm{b}}$ Department of Horticulture, Faculty of Agriculture, Bursa Uludag University, Bursa. Turkey \\ ${ }^{\mathrm{c}}$ Department of Biology, Faculty of Arts and Sciences, Bolu Abant Izzet Baysal University, 14280 Bolu. Turkey
}

(Received: 25 May 2019; accepted: 8 July 2019)

\begin{abstract}
Globe artichoke (Cynara scolymus L.) is a perennial plant belonging to Asteraceae family. It is one of the most suitable plants for growing organically. Artichoke has been used as choleretic, hepatoprotective, anticarcinogenic, antioxidant, antibacterial, antifungal, antimicrobial, cholesterol-reducing, and diuretic in traditional medicine. Artichoke has been cultivated worldwide because of its nutritional value and medicinal properties. In this study organically and conventionally grown artichokes were compared in terms of phenolic constituents, antibacterial and antioxidant activities. Artichoke leaves, bracts, and floral receptacles obtained from 2 different sources (organic and conventional) were freeze-dried, powdered, and extracts were prepared with methanol. Phenolic constituents (chlorogenic acid, cynarin, luteolin, and apigenin) were analysed by HPLC-DAD system. It was found that organic farming enhanced cynarin, chlorogenic acid, and luteolin amounts in receptacle (edible part). Organically grown leaves had also higher amounts of cynarin and chlorogenic acid than conventional ones. Cynarin amount was higher by $35 \%$ in organic receptacle and $20 \%$ in organic leaves. Organic farming also augmented the antioxidant property and flavonoid content of edible parts of the artichoke. Additionally, organically grown leaves had the highest antioxidant activity, total phenol and flavonoid contents. Antibacterial activity was observed with both organic and conventional leaves only against Staphylococcus epidermidis. This comparative study revealed that organic farming enhanced the health-beneficial medicinal values of artichoke's heart and leaves.

Keywords: antibacterial, antioxidant, artichoke, conventional, Cynara scolymus, flavonoid, HPLC organic, phenol
\end{abstract}

Cynara scolymus L. [synonym of Cynara cardunculus L. var. scolymus (L.) Fiori] known as globe artichoke is a perennial, rosette plant belonging to Asteraceae family (LATTANZIO et al., 2009). It is an ancient crop and medicinal plant originating from the Mediterranean area, that is widely cultivated all over the world nowadays for its large fleshy flower head or capitula (immature inflorescence) (NEGRo et al., 2012; SEKARA et al., 2015). The edible part of the artichoke is floral receptacle commonly known as "heart" (CHRISTAKI et al., 2012). It has been widely used for human nutrition and is valuable in pharmaceutical industries (LATTANZIO et al., 2009). Artichoke has hepatoprotective, antioxidant, anticarcinogenic, hypocholesterolemic, antibacterial, anti-HIV, choleretic, and diuretic activities (NEGRO et al., 2012). Nutritional and pharmaceutical value of globe artichoke heads and leaves are ascribed to having high levels of polyphenolic compounds, inulin, fibre, and minerals (LATTANZIO et al., 2009). The remarkable medicinal potential of this plant is mainly due to flavonoids and phenolic acids, particularly caffeic acid and its derivatives, mono and dicaffeoylquinic acids

\footnotetext{
* To whom correspondence should be addressed.

Phone: +90 37425412 38; fax: +90 37425346 42; e-mail: turker_a@ibu.edu.tr
} 
(NEGRO et al., 2012). Because of the strong structure of the artichoke and the many positive effects on human health, it has been pointed out that it is an ideal plant for growing organically (BAŞAY, 2016).

The objective of this study was to reveal the difference in phenolic profiles, antioxidant and antimicrobial activities between organically and conventionally grown artichokes.

\section{Materials and methods}

\subsection{Plant materials}

Artichokes (Bayrampaşa cultivar) grown by organic and conventional methods used in the study were cultivated by Dr. Sevinç Başay. Organic artichokes were grown in organic area of Nilufer Municipality Kent Bostanları, Ürünlü village, Bursa. They were grown according to the principles of organic farming. Conventional artichokes were also grown in conventional area of Ürünlü village, Bursa. Young leaves and heads at commercial maturity (diameter more than $7 \mathrm{~cm}$ ) were collected from 5 different plants in May 2017 and 2018. Five heads were used for each measurement.

\subsection{Extract preparation}

Floral receptacles, all bracts of the heads and leaves obtained from 2 different sources (organic and conventional) were freeze dried, powdered, and extracted with methanol solvent at $40{ }^{\circ} \mathrm{C}$ in water bath for 18 hours and then vacuum evaporated. The residue was dissolved in water and then lyophilized to obtain powdered extract. Yield for each extract was calculated and are listed in Table 1. Extract yields were determined with the formula

"Yield $(\%)=$ Weight of extract $(\mathrm{g}) /$ powdered plant material $(\mathrm{g}) \times 100 "$.

Table 1. Contents of phenolic compounds and extraction yield (\%) in artichoke methanol extracts

\begin{tabular}{|c|c|c|c|c|c|c|}
\hline \multirow[b]{3}{*}{ Phenols } & \multicolumn{6}{|c|}{ Artichoke extracts ( $\mathrm{mg} \mathrm{g}^{-1}$ dry extract) } \\
\hline & \multicolumn{2}{|c|}{ Receptacle } & \multicolumn{2}{|c|}{ Bract } & \multicolumn{2}{|c|}{ Leaf } \\
\hline & $\mathrm{O}$ & $\mathrm{C}$ & $\mathrm{O}$ & $\mathrm{C}$ & $\mathrm{O}$ & $\mathrm{C}$ \\
\hline Chlorogenic acid & $17.74 \pm 0.01^{\mathrm{d}}$ & $13.74 \pm 0.01^{\mathrm{f}}$ & $16.39 \pm 0.01^{\mathrm{e}}$ & $21.01 \pm 0.00^{\mathrm{c}}$ & $53.37 \pm 0.01^{\mathrm{a}}$ & $30.87 \pm 0.01^{b}$ \\
\hline Cynarin & $30.58 \pm 0.02^{\mathrm{d}}$ & $19.81 \pm 0.05^{\mathrm{e}}$ & $43.33 \pm 0.07^{\mathrm{b}}$ & $48.10 \pm 0.09^{\mathrm{a}}$ & $47.98 \pm 0.00^{\mathrm{a}}$ & $38.30 \pm 0.10^{\mathrm{c}}$ \\
\hline Luteolin & $0.17 \pm 0.00^{\mathrm{e}}$ & $0.05 \pm 0.01^{\mathrm{f}}$ & $0.73 \pm 0.00^{\mathrm{d}}$ & $0.93 \pm 0.00^{\mathrm{c}}$ & $7.29 \pm 0.01^{\mathrm{b}}$ & $13.57 \pm 0.00^{\mathrm{a}}$ \\
\hline Apigenin & - & - & - & - & - & - \\
\hline Extraction yield (\%) & 12.0 & 18.0 & 24.0 & 12.6 & 21.7 & 15.9 \\
\hline
\end{tabular}

Data were presented as a mean \pm standard error (SE). Means with the same letter within rows are not significantly different at $\mathrm{P}>0.05$. O: Organic; $\mathrm{C}$ : conventional

\subsection{High performance liquid chromatography (HPLC) analysis of phenolics}

Methanolic extracts were quantitatively analysed for chlorogenic acid, cynarin, luteolin 7-glucoside, and apigenin $\left(\right.$ Carbosynth $^{\circledR}$ ) using high performance liquid chromatography (HPLC) coupled with a diode array detector (DAD) (VWR-Hitachi LaChrom Elite ${ }^{\circledR}$ ). The 
operating conditions were arranged as described previously in our laboratory (YILDIRIM et al., 2017). The chromatograms were recorded at $325 \mathrm{~nm}$ for chlorogenic acid, $330 \mathrm{~nm}$ for cynarin, $350 \mathrm{~nm}$ for luteolin, and 340 for apigenin.

\subsection{Antioxidant activity, total phenol and flavonoid contents}

Antioxidant, total phenol and flavonoid potentials of artichoke methanol extracts were determined using 2,2-diphenyl-1-picrylhydrazil (DPPH•, Sigma ${ }^{\circledR}$ ) radical photometric assay (Blois, 1958), Folin-Ciocalteu (Slinkard and Singleton, 1977)] and aluminum chloride $\left(\mathrm{AlCl}_{3}\right)$ colorimetric assays (ZHISHEN et al., 1999), respectively, with some modifications in our laboratory (YILDIRIM et al., 2017).

\subsection{Antibacterial assay}

Antibacterial effect of each plant extract was investigated to evaluate against 10 human pathogenic bacterial strains by using disc diffusion method (ANDREWs, 2009) with some modifications (YILDIRIM et al., 2017). Gram positive [Streptococcus pyogenes (ATTC 19615), Staphylococcus aureus (ATTC 25923), and S. epidermidis (ATCC 12228)] and Gram negative [Escherichia coli (ATCC 25922), Enterobacter cloacea (ATCC 23355), Salmonella typhimurium (ATCC 14028), Serratia marcescens (ATCC 8100), Klebsiella pneumoniae (ATCC 13883), Proteus vulgaris (ATCC 13315), and Pseudomonas aeruginosa (ATCC 27853)] bacteria (Becton Dickinson Laboratories, France) were tested.

\subsection{Statistical analysis}

Data analysis was conducted using analysis of variance (ANOVA) and Duncan's multiple range tests using SPSS vers. 15 (SPSS Inc, Chicago, IL, USA).

\section{Results and discussion}

Quantification of four phenols in methanol extracts of artichoke was conducted with HPLCDAD analysis and the results are summarized in Table 1. The chromatogram of the used standards is shown in Figure 1. Cynarine was the most abundant among the analysed artichoke parts. Especially, the amount of cynarin in the organically grown receptacle (edible part) was much higher than the amount in the conventional receptacle. Receptacle part of the artichokes grown organically also contained more chlorogenic acid and luteoline than those grown conventionally. Organic farming enhanced chlorogenic acid and cynarin amounts in receptacle ( $23 \%$ and $35 \%$, respectively) and leaves ( $42 \%$ and $20 \%$, respectively) in our study (Table 1). Similar to our findings, Leskovar and OTHмAN (2018) evaluated the effect of organic and conventional chemical fertilizers on head quality. It was found that chlorogenic acid and cynarin contents rose to $31 \%$ and $12 \%$, respectively, with organic farming. Bracts and leaves included more cynarin than receptacle. Leaf parts of the oganically grown artichokes contained more cynarin and chlorogenic acid than the conventionaly grown ones (Table 1). Generally, artichoke leaves had more phenols than other parts. Chlorogenic acid was found in the highest amount in organically grown artichoke leaves. Consistent with our results, Negro and co-workers (2012) found that total polyphenols (chlorogenic acid, cynarin, and luteolin) were more abundant in artichoke leaves than in heads. On the other hand, in our study luteolin was detected in the highest amount in conventionally grown 
leaves. Organic leaves and conventional bracts had the highest cynarin amount. Luteolin amount was lower than cynarin and chlorogenic acid in all parts of artichoke, and the highest amount was observed in conventionally grown leaves. Similar to our results, PANDINO and co-workers (2011) reported that the content of luteolin and its derivatives were low in all studied parts of the artichoke cultivars. In another study, artichoke leaf extracts were investigated and compared for their flavonoids such as luteolin glycosides (MuLINACCI et al., 2004). It was found that the amount of luteolin 7-O-glucoside ranged from $1.00 \mathrm{mg} \mathrm{g}^{-1}$ to $2.92 \mathrm{mg} \mathrm{g}^{-1}$ in the studied extracts. Their findings in terms of luteolin glycoside were approximately 3 or 5 times lower than our findings. PÉREZ-EsTEVE and co-workers (2018) reported that chlorogenic acid was the most abundant followed by apigenin and cynarin that accumulated mainly in the receptacle and inner bracts of artichokes. On the other hand, apigenin was not detected in any tested artichoke parts (Table 1). Apigenin in our tested extracts might be converted into luteolin and its conjugates (PANDINO et al., 2011).

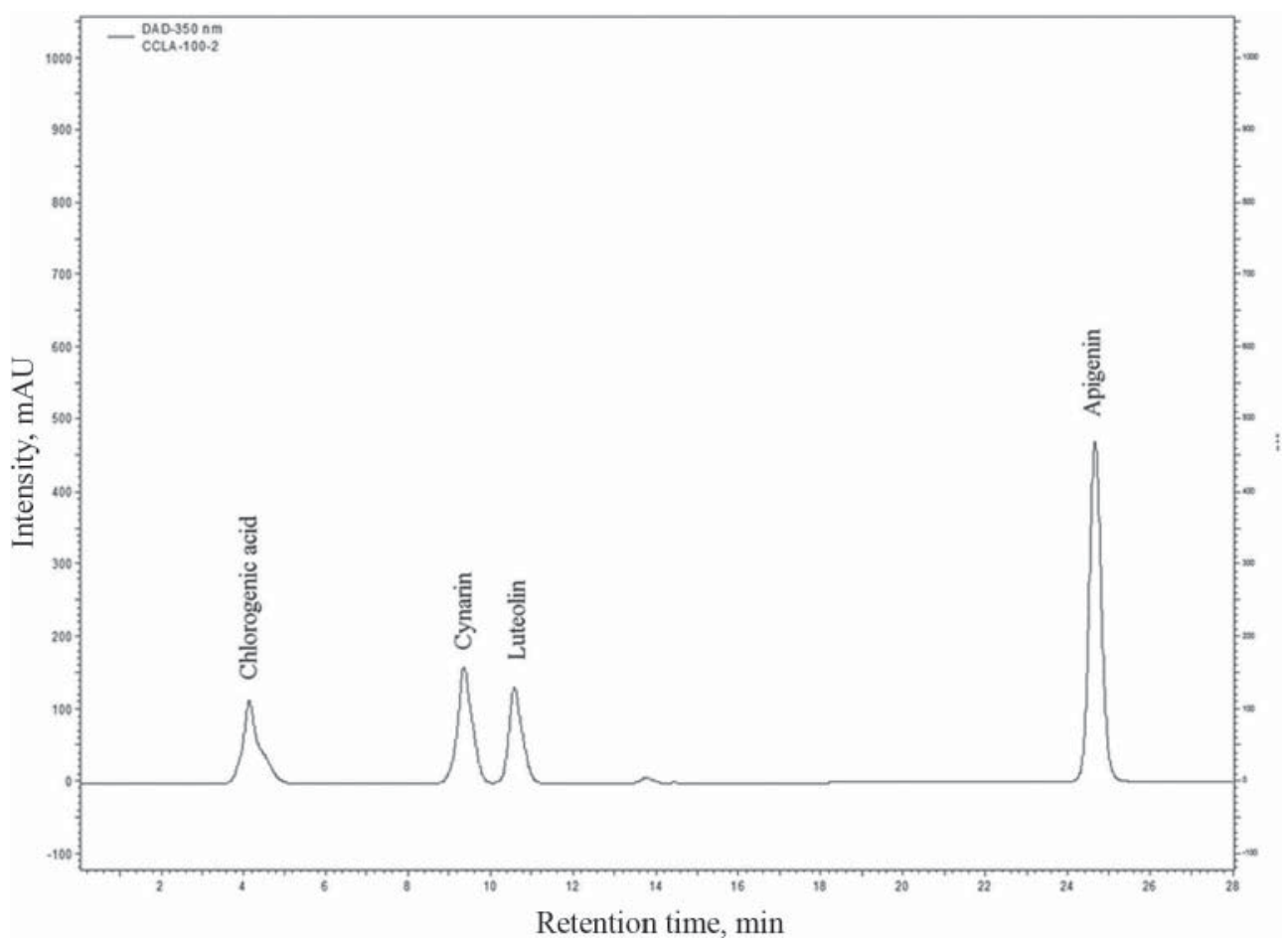

Fig. 1. Chromatogram of the standards. Retention times: 1. chlorogenic acid - $4.11 \mathrm{~min}$; 2. cynarin - $9.31 \mathrm{~min}$; 3. luteolin - $10.55 \mathrm{~min} ; 4$. apigenin - $27.44 \mathrm{~min}$

Antioxidant activity of artichoke extracts was evaluated with DPPH free radical scavenging capacity. $\mathrm{IC}_{50}$ values of artichoke extracts were assessed and the best antioxidant activity was obtained with organically grown leaves having $\mathrm{IC}_{50}$ value of $446.5 \mu \mathrm{g} \mathrm{ml}^{-1}$. Tested artichoke parts displayed moderate antioxidant activity. Antioxidant activity of organic receptacle and leaves was higher than of the conventional ones (Table 2). Similar to the $\mathrm{IC}_{50}$ value of organic receptacle that we found $\left(1.067 \mathrm{mg} \mathrm{ml}^{-1}\right)$, KolLIA and co-workers (2017) 
published $\mathrm{IC}_{50}$ of classical extraction of globe artichoke head as $1.17 \mathrm{mg} \mathrm{ml}^{-1}$. SALEM and coworkers (2017) reported that ethanol extract of artichoke leaves had the highest antioxidant activity at $400 \mu \mathrm{g} \mathrm{ml}^{-1}$ concentration with $94.23 \%$ inhibition. Contrary to this study, methanol extract of conventionally grown leaves showed $50 \%$ inhibition at $586.2 \mu \mathrm{g} \mathrm{ml}^{-1}$ concentration in our study (Table 2). In another study, it was reported that ethanol extract of artichoke leaves showed the highest antioxidant activity with $\mathrm{IC}_{50}$ value of $5.9 \mathrm{mg} \mathrm{m}^{-1}$ (VAMANU et al. 2011). However, organic and conventional leaves showed higher antioxidant activity in our study having $\mathrm{IC}_{50}$ values of $0.45 \mathrm{mg} \mathrm{ml}^{-1}$ and $0.59 \mathrm{mg} \mathrm{ml}^{-1}$, respectively.

Table 2. $\mathrm{IC}_{50}$ values, total phenol and flavonoid contents of artichoke methanol extracts

\begin{tabular}{|c|c|c|c|c|c|c|}
\hline & \multicolumn{2}{|c|}{ Receptacle } & \multicolumn{2}{|c|}{ Bract } & \multicolumn{2}{|c|}{ Leaf } \\
\hline & $\mathrm{O}$ & $\mathrm{C}$ & $\mathrm{O}$ & $\mathrm{C}$ & $\mathrm{O}$ & $\mathrm{C}$ \\
\hline $\begin{array}{l}\text { Antioxidant activity } \mathrm{IC}_{50} \\
\left(\mu \mathrm{g} \mathrm{ml}^{-1}\right)\end{array}$ & $1067.4 \pm 1.1^{\mathrm{e}}$ & $1460.0 \pm 1.4^{\mathrm{f}}$ & $784.3 \pm 1.1^{\mathrm{d}}$ & $743.8 \pm 1.2^{\mathrm{c}}$ & $446.5 \pm 1.0^{\mathrm{a}}$ & $586.2 \pm 1.1^{\mathrm{b}}$ \\
\hline $\begin{array}{l}\text { Total phenol } \\
\text { (mg GAE/g dry extract) }\end{array}$ & $48.3 \pm 2.1^{\mathrm{d}}$ & $48.5 \pm 2.3^{d}$ & $55.0 \pm 0.6^{\mathrm{c}}$ & $89.2 \pm 2.2^{\mathrm{a}}$ & $90.8 \pm 2.0^{\mathrm{a}}$ & $76.2 \pm 2.0^{\mathrm{b}}$ \\
\hline $\begin{array}{l}\text { Total flavonoid } \\
\text { (mg QE/g dry extract) }\end{array}$ & $84.7 \pm 0.4^{\mathrm{e}}$ & $76.7 \pm 0.1^{\mathrm{f}}$ & $126.1 \pm 0.1^{\mathrm{d}}$ & $177.0 \pm 0.1^{\mathrm{c}}$ & $291.8 \pm 0.1^{\mathrm{a}}$ & $215.6 \pm 0.0^{\mathrm{b}}$ \\
\hline
\end{tabular}

Data were presented as a mean \pm SE. Means with the same letter within rows are not significantly different at $\mathrm{P}>0.05 . \mathrm{IC}_{50}$ : The half maximal inhibitory concentration. GAE: Gallic acid equivalent; QE: quercetin equivalent

Total phenolic content of artichoke extracts was calculated from the gallic acid calibration curve $\left(\mathrm{R}^{2}=0.9987\right)$. Organically grown leaves and conventionally grown bracts contained higher amounts of phenol than other extracts expressed as milligrams of gallic acid equivalents (GAE) (90.8 and $89.2 \mathrm{mg} \mathrm{GAE} / \mathrm{g}$ dry extract, respectively) (Table 2). Total flavonoid content of artichoke extracts was calculated from the quercetin calibration curve $\left(\mathrm{R}^{2}=0.9996\right)$. Organically grown leaves had the highest total flavonoid content expressed as milligrams of quercetin equivalents (QE) (291.8 mg QE/g dry extract) (Table 2). Organically and conventionally grown artichoke leaves and bracts contained more total phenol and flavonoids than the receptacle. Organic artichoke leaves had more phenol and flavonoids than conventional leaves. There was no difference in total phenolic content between organic and conventional receptacles. However, organic receptacle contained more flavonoid than conventional one. Conventional bracts had more total phenol and flavonoid content than organic ones (Table 2). In agreement with our data, JiMENEZ-EsCRIG and co-workers (2003) observed the total phenolic content of aqueous methanol extract of receptacle as $50.04 \mathrm{mg}$ QE/g dry extract. On the other hand, some studies reported lower total phenol and flavonoid content of artichoke leaves than our findings. For example, SALEM and co-workers (2017) reported that total phenol and flavonoid contents of ethanol extract of artichoke leaves were $54.54 \mathrm{mg} \mathrm{GAE} / \mathrm{g}$ dry extract and $12.00 \mathrm{mg}$ Catechin Equivalent/g dry extract, respectively. Moreover, VAMANU and co-workers (2011) showed the total phenol and flavonoid content of dried leaves of ethanol extract of artichoke as $49.1 \mathrm{mg} \mathrm{GE} / \mathrm{g}$ and $179.4 \mathrm{mg} \mathrm{QE} / \mathrm{ml}$, respectively.

Both organically and conventionally grown leaves had strong antibacterial activity against $S$. epidermidis. It was the only bacterium susceptible to these extracts among the 10 bacteria studied (Table 3). Contrary to our result, ÇOBAN and BIYIK (2010) reported that ethanol extracts of $C$. scolymus leaves had no activity against S. epidermidis. ZHU and co- 
workers (2004) showed that chloroform, ethyl acetate, and n-butanol extracts of artichoke leaves displayed antibacterial activity against S. aureus, E. coli, P. aeruginosa, and S. typhimurium. Mossi and ECHEVERRIGARAY (1999) demonstrated the antibacterial activity of dichloromethanic extract of artichoke leaves against S. aureus, Bacillus cereus, and B. subtilis. VAMANU and co-workers (2011) investigated the antibacterial activity of artichoke leaves extracted with different percentages of ethanol, and it was found that E. coli, $P$. aeruginosa, and S. aureus were sensitive to $97 \%$ ethanol extract of artichoke leaves. In contrast to these studies, above mentioned bacteria were not susceptible to methanolic artichoke leaf extract in our study (Table 3). Szymon Syrenius mentioned alcohol extracts of leaves and roots of artichoke for the treatment of skin diseases such as scabies in "Zielnik Herbarzem Zwany" in 1613, Krakow (SEKARA et al., 2015). Noticeable antibacterial activity of artichoke against $S$. epidermidis may explain why this plant has been used in traditional medicine in the treatments of skin diseases.

Table 3. Antibacterial activities of artichoke methanol extracts. Data were presented as a mean diameter of inhibition zones $\pm \mathrm{SE}$. Means with the same letter within rows are not significantly different at $\mathrm{P}>0.05$

\begin{tabular}{|c|c|c|c|c|}
\hline \multirow[t]{3}{*}{ Pathogens } & \multicolumn{4}{|c|}{ Diameter of inhibition zone $(\mathrm{mm} \pm \mathrm{SE})$} \\
\hline & \multicolumn{2}{|c|}{ Leaf } & \multicolumn{2}{|c|}{ Controls } \\
\hline & $\mathrm{O}$ & $\mathrm{C}$ & Ampicillin & Penicillin \\
\hline S. auerus & - & - & $33.7 \pm 0.9^{b}$ & $35.3 \pm 0.3^{\mathrm{a}}$ \\
\hline S. epidermidis & $14.0 \pm 0.4^{\mathrm{c}}$ & $14.7 \pm 0.2^{\mathrm{c}}$ & $32.0 \pm 0.6^{\mathrm{a}}$ & $22.8 \pm 0.5^{\mathrm{b}}$ \\
\hline S. marcescens & - & - & - & - \\
\hline S. pyogenes & - & - & $50.5 \pm 1.4^{\mathrm{a}}$ & - \\
\hline S. typhimurium & - & - & $25.3 \pm 0.7^{\mathrm{a}}$ & - \\
\hline P. aeruginosa & - & - & - & - \\
\hline P. vulgaris & - & - & $28.7 \pm 0.9^{\mathrm{a}}$ & $25.3 \pm 0.3^{b}$ \\
\hline K. pneumonia & - & - & - & - \\
\hline E. cloacae & - & - & $25.0 \pm 0.6^{\mathrm{a}}$ & $15.0 \pm 0.4^{\mathrm{b}}$ \\
\hline E. coli & - & - & $21.7 \pm 0.7^{\mathrm{a}}$ & - \\
\hline
\end{tabular}

Data were presented as a mean diameter of inhibition zones \pm SE. Means with the same letter within rows are not significantly different at $\mathrm{P}>0.05$

\section{Conclusions}

Comparison of organically and conventionally grown artichokes showed that organic farming enhanced the medicinal value and quality of edible part of artichoke (receptacle). Pharmaceutically valuable cynarin, chlorogenic acid, and luteolin amounts in receptacle increased with organic growing. Likewise, antioxidant property and total flavonoid content of receptacle were improved with organic farming. Organically grown leaves had the highest cynarin and chlorogenic acid amount, antioxidant activity, total phenol and flavonoid contents. Medicinal value of artichoke leaves is very noteworthy and it is also elevated with organic production. Antibacterial activity of the leaves against S. epidermidis was revealed for the first time. Polyphenol content and antioxidant activity of the artichoke leaves were very impressive, and this artichoke part should be given a chance as a nutraceutical product. 
This study was supported by Bolu Abant Izzet Baysal University Research Foundation (BAP 18.03.01.1275).

\section{References}

ANDrEws, J.M. (2009): BSAC standardized disc susceptibility testing method (version 8). J. Antimicrob. Chemoth., $64,454-489$.

BAşAY, S. (2016): The artichoke (Cynara scolymus L.) as ideal plant for organic growing. J. Agric. Fac. Uludag Univ., 30, 647-653.

BLoIs, M.S. (1958): Antioxidant determinations by the use of a stable free radical. Nature, 181, 1199.

Christaki, E., Bonos, E. \& Florou-PAneri, P. (2012): Nutritional and functional properties of Cynara crops (Globe Artichoke and Cardoon) and their potential applications: A review. IJAST, 2, 64-70.

ÇOBAn, E.P. \& BIYIK, H. (2010): Antimicrobial activity of the ethanol extracts of some plants natural growing in Aydın, Turkey. Afr. J. Microbiol. Res., 4, 2318-2323.

Jimenez-Escrig, A., Dragsted, L.O., Daneshvar, B., Pulido, R. \& Saura-Calixto, F. (2003): In vitro antioxidant activities of edible artichoke (Cynara scolymus L.) and effect on biomarkers of antioxidants in rats. J. Agr. Food Chem., 51, 5540-5545.

Kollia, E., Markaki, P., Zoumpoulakis, P. \& Proestos, C. (2017): Antioxidant activity of Cynara scolymus L. and Cynara cardunculus L. extracts obtained by different extraction techniques. Nat. Prod. Res., 31, 1163-1167.

Lattanzio, V., Kroon, P. A., Linsalata, V. \& Cardinali, A. (2009): Globe artichoke: a functional food and source of nutraceutical ingredients. J. Funct. Foods, 1, 131-144.

Leskovar, D. \& Othman, Y.A. (2018): Organic and conventional farming differentially influenced soil respiration, physiology, growth and head quality of artichoke cultivars. J. Soil Sci. Plant Nut., 18, 865-880

Mossi, A.J. \& Echeverrigaray, S. (1999): Identification and characterization of antimicrobial components in leaf extracts of globe artichoke (Cynara scolymus L.). Acta Hortic., 501, 111-114.

Mulinacci, N., Prucher, D., Peruzzi, M., Romani, A., Pinelli, P., Giaccherini, C. \& Vincieri, F.F. (2004): Commercial and laboratory extracts from artichoke leaves: estimation of caffeoyl esters and flavonoidic compounds content. J. Pharm. Biomed. Anal., 34, 349-357.

Negro, D., Montesano, V., Grieco, S., Crupi, P., Sarli, G., De Lisi, A. \& Sonnante, G. (2012): Polyphenol compounds in artichoke plant tissues and varieties. J. Food Sci., 77, 244-252.

Pandino, G., Lombardo, S., Mauromicale, G. \& Williamson, G. (2011): Profile of polyphenols and phenolic acids in bracts and receptacles of globe artichoke (Cynara cardunculus var. scolymus) germplasm. J. Food Compos. Anal., 24, 148-153.

Pérez-Esteve, É., Salata, A., Barat, J.M., Stępniowska, A., López-Galarza, S. \& Nurzyńska-Wierdak, R. (2018): Polyphenolic composition of Spanish cultivars of globe artichoke (Cynara cardunculus L. var. scolymus (L.) Fiori). Acta Sci. Pol.-Hortoru., 17, 177-184.

Salem, M.B, Affes, H., Athmouni, K., Ksouda, K., Dhouibi, R., ... \& Zeghal, K.M. (2017): Chemicals compositions, antioxidant and anti-inflammatory activity of Cynara scolymus leaves extracts, and analysis of major bioactive polyphenols by HPLC. Evid. Based Compl. Alt., 4951937, 1-14.

Sekara, A., Kalisz, A., Gruszecki, R., Grabowska, A. \& Kunicki, E. (2015): Globe artichoke-a vegetable, herb and ornamental of value in central Europe. J. Hortic. Sci. Biotech., 90, 365-374.

SlinKard, K. \& Singleton, V.L. (1977): Total phenol analysis: automation and comparison with manual methods. Am. J. Enol. Vitic., 28, 49-55.

Vamanu, E., Vamanu, A., Nita, S. \& Colceriu, S. (2011): Antioxidant and antimicrobial activities of ethanol extracts of Cynara scolymus (Cynarae folium, Asteraceae family). Trop. J. Pharm. Res., 10, 777-783.

Yildirim, A.B., GunER, B., KARAKAS, F.P. \& TuRKer, A.U. (2017): Evaluation of antibacterial, antitumor, antioxidant activities and phenolic constituents of field-grown and in vitro-grown Lysimachia vulgaris L. Afr. J. Tradit. Complem., 14, 177-187.

Zhishen, J., MengCheng, T. \& JiAnming, W. (1999): The determination of flavonoid contents in mulberry and their scavenging effects on superoxide radicals. Food Chem., 64, 555-559.

Zhu, X., Zhang, H. \& Lo, R. (2004): Phenolic compounds from the leaf extract of artichoke (Cynara scolymus L.) and their antimicrobial activities. J. Agr. Food Chem., 52, 7272-7278. 